\title{
The Potential of Developing New Energy Auto Industry in 'Capital of Hydropower'
}

\author{
Chenggang $X u^{1, a}$, Qianhui $X u^{2, b}$ \\ ${ }^{1}$ College of Economics \& Management, Three Gorges University, Yichang, Hubei, 443002, China \\ ${ }^{2}$ Shi Liangcai School of Journalism and Communication, Zhejiang Sci-Tech University, Hangzhou, \\ Zhejiang,310000, China \\ ammm98@126.com, ${ }^{\mathrm{b}}$ nnn98@sina.com
}

Keywords: pure electric auto, Yichang ,hydropower resources ,green standard ,industrial chain Abstract. The development of new energy auto in Yichang can give full play to the cost advantage of' capital of hydropower' .Using the 'parallel import policy' and adopting CKD to organize production can rapidly cultivate production conditions and consumption market. Under the restriction of high standard emission along the Yangtze River, Yichang is forced by the inverted logic relationship of the carbon emission to achieve green standard breakthroughs and institutional innovation in terms of technology, environment, behavior, law and culture, so as to set up a new model of environment-friendly city.

\section{Introduction}

Yichang has the policy resources of the Free Trade Zone, make use of the cheap electricity of the 'capital of hydropower' and can create the non imitative features of other cities.

We put forward the development ideas of first cultivating the consumer market, next building industry. Its industry status is changed through the development of new energy auto ,relying on the characteristics of the dense automobile industry in Hubei to create a new city model for the consumption and production of new energy automobile. This is one of the necessary conditions for building a characteristic Yichang, also is a way to explore China's industrial transformation to realize the experience accumulation of the 2025 Chinese Manufacturing Model.

\section{Opportunity}

The favorable conditions and opportunities for the development of new energy auto industry in Yichang are:

\section{The Promulgation of the 'Double Integral' Management Method for Automobile}

China implements the double integral plan of automobile in 2018. The State Council proposed that the proportion of new energy auto in 2018-2020 was $8 \%, 10 \%, 12 \%$, respectively. When enterprises complete the own output of the car in the year, at the same time the output of new energy vehicles must be completed according to the above proportion.

This'parallel management method' will make the promotion of the new energy vehicle shift from 'policy driven' to 'law driven'. That adds pressure to large domestic traditional fuel car companies. For Yichang, the opportunity can be taken to introduce new energy car projects, find a way to solve the pressure for domestic leading enterprises, and also provide a rare opportunity for themself to break through the industrial structure.

\section{China (Hubei) Free Trade Test Zone Established in Yichang District}

The Yichang District officially started operation in April 1, 2017.According to the construction plan, that focus on the development of electronic information, biomedicine, equipment manufacturing, cross-border e-commerce, financial leasing and other industries.

Based on the strategic positioning, functional differences, mechanism building, collaborative demonstration and institutional innovation Yichang Free Trade Zone will explore all aspects of the 
practice of China's theory and China's experience in the establishment of Free Trade Zone. policy resources provide a wide range of development for Yichang. So the field of practice are not restricted by the above.

\section{Yichang's Development Status}

In May 26, 2016, the'Yichang test' of ecological management of the Three Gorges Ecological Economic Cooperation Zone was officially launched in Yichang, and became the first ecological control test area in the country.

As an important member of the Three Gorges city group, Yichang explores the regional ecological protect, ecological financial and ecological capital, which it is a set of 'collaborative innovation with Government, enterprises, universities, institutions, applications', one of the five. This'test' has formed an inverted logic driving relationship, that is, in the development of new energy auto Yichang the first step should achieve innovation in the standards and norms of technology, environment, behavior, the legal system, the humanities and other aspects, to meet the requirements of ecological protection. Secondly, then it's a new path between protection and development.

Based on the above three important events, it provides unprecedented opportunities for the construction of Yichang's new energy auto industry.

\section{Technical strategy}

In order to meet the needs of the construction and development of the ecological economic circle of the Yangtze River, according to the requirements of energy saving, environmental protection and safety, the policy resources which the state grants Hubei Free Trade Zone (Yichang section) should be made good use of and advantage of the full.

Using the 'Parallel Import' Policy. Since February 15, 2015, the test of the policy of the parallel import cars in Shanghai Free Trade Zone began.It bypasses the sales links of the general dealers, the large area dealers and the $4 \mathrm{~S}$ stores, and saves a lot of intermediate links. There is an obvious advantage over the ordinary import cars of China in price, car type, delivery time, configuration of type and delivery process. Using this policy, Yichang can start the consumer market of new energy car with priority and speed up the cultivation of consumer market.

Starting with CKD Assembly. CKD(Completely Knocked Down) assembly is to import the mode of the finished automobile in the form of bulk parts. The auto parts is made in a developed country with higher production cost or higher level of production technology, and the finished autos are assembled and sold at a lower retail price in the cheaper labor country.

In this way, Yichang can take advantage of the local cheaper labor force and enjoy a certain import tariff that is lower than the ordinary import automobile, promote locally the rapid development of the new energy auto industry and increase the employment opportunities.

In the early stage of developing market, Yichang adopts CKD and SKD (semi bulk) production mode to maintain the leading position of the technology in the world and to be flexible in the changing environment. And can avoids a large amount of sunk cost and form a higher exit barrier. When the automobile market downturn, this way provides an exit mechanism for industry, foster an agile ecology of new energy automobile industry. At the same time, the rhythm of localization production and pollutant discharge can be effectively controlled, and both harmonious promotion can be realized[1].

Construction of Industrial Chain. The basic path of the development strategy of automobile industrialization should be from simple to compound, from single to multiple and from manufacturing to service. Yichang revolves around the axis of new energy automobiles, and gradually builds a new auto industry base of production, trade, R \& D and waste treatment.

The development of electric automobile has made the industry chain of traditional automobile face a great challenge. The three main components of the electric automobile: the power battery, the electric control system and the drive motor will make the car structure more simple. The investment scale of production is reduced, the entry threshold is lowered, and the competition of enterprises is 
more intense. In addition to the three components of the whole industry chain, the power grid, the independent $\mathrm{R} \& \mathrm{D}$ and the independent brand will be the most profitable. The rare earth resources of which produce permanent magnet synchronous motor have certain monopoly (The production of sintered Nd-Fe-B magnets in China accountes for $80 \%$ ratio of the global) [2]; Lithium in the production of power batteries is rich in China, Australia, Chile and Argentina[3]. China is rich in hydropower resources (there just are Three Gorges, Gezhouba Dam, Qingjiang, three state power suppliers of hydropower in Yichang).Under this condition, the content of the value chain will be different from the traditional automobile industry, as shown in Fig. 1.

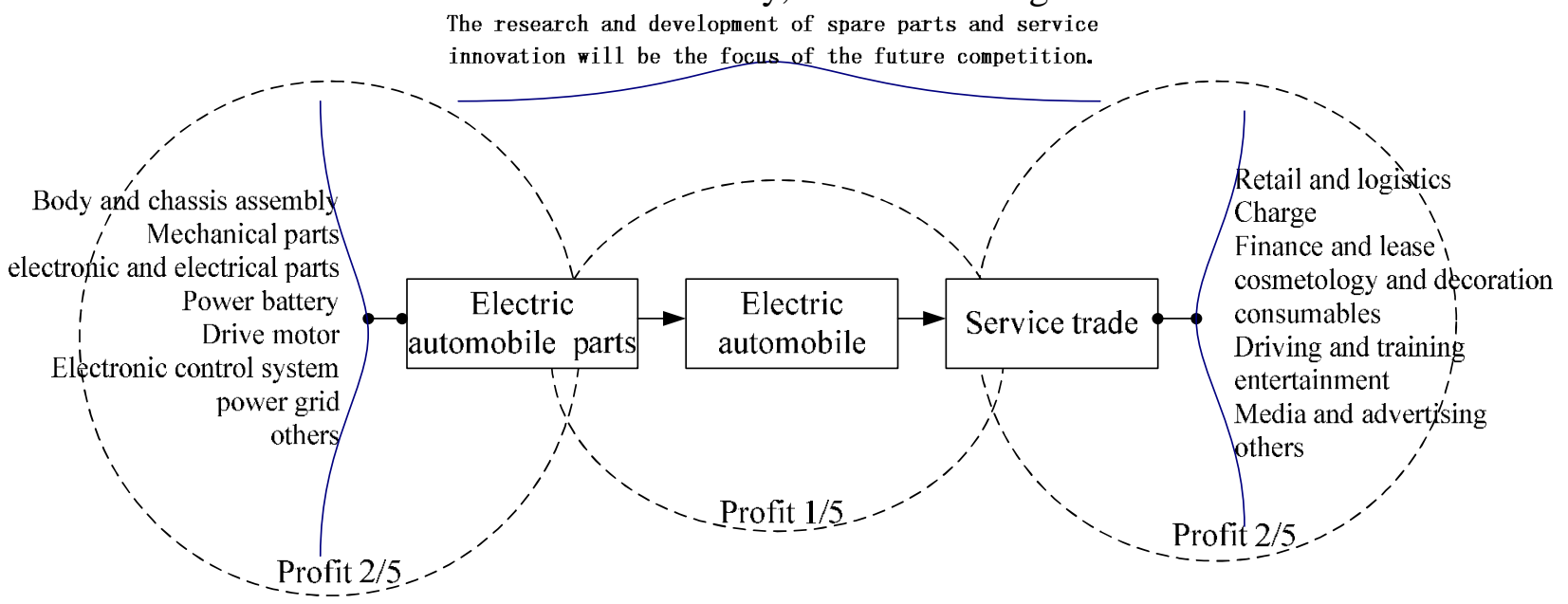

Fig. 1 Profit composition of industrial value chain of electric automobile

\section{Green standard}

'Yichang test' on the ecological management of the Three Gorges Eco-economic Cooperation Zone in 'Capital of Hydropower' formes a inverted logical development path for the development of new energy auto in technology, environment, public behavior, legal system, and humanity standards or norms (see Fig. 2). First the ecological protection standards are formulated. then the related subitems of automobile industry are introduced step by step. Yichang should create a new green standard for the whole country in the aspects of carbon emission reduction, manufacturing enterprise layout, water resources protection, labor employment and other ecological civilization constructions.

Yichang should seek a breakthrough in combination with the national policy. It is taken full advantage of the opportunity for the government approve to the Hubei Free Trade Zone(Yichang section) .Policy breakthroughs and institution innovation are achieved in the production, demonstration of the use and promotion of new energy autos to create the environment for the development of energy-saving automobile industry.

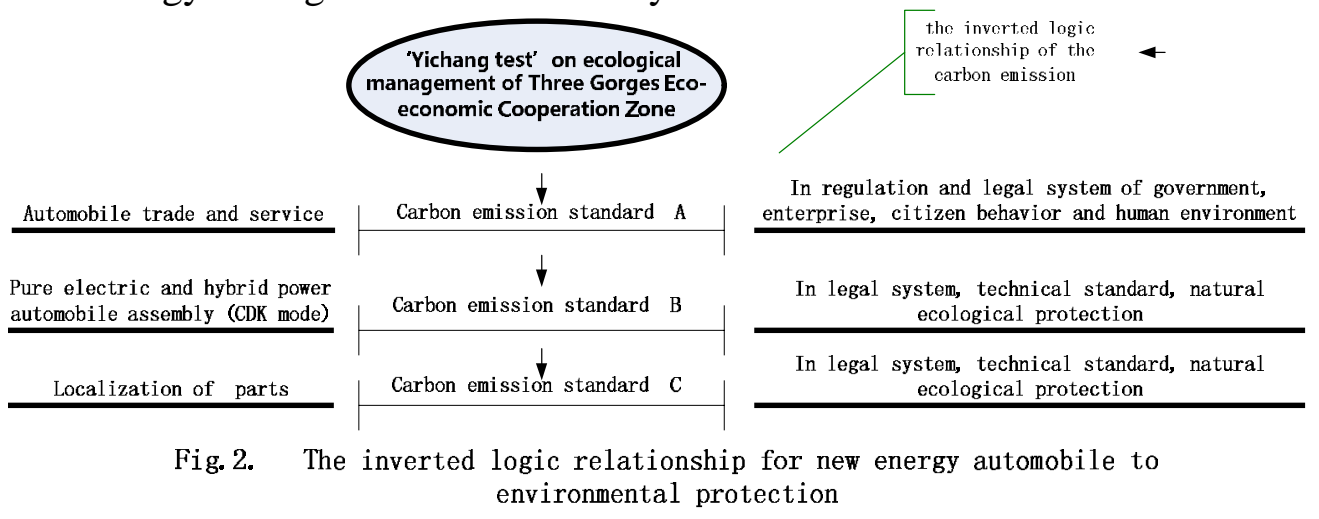

Yichang should apply for pilot about the comprehensive cultivation of a consumption market of new energy car to Central Government and the Hubei provincial government . these contents include: 
(1) Under the equilibrium both the protection of the drinking water and the development of the pure electric auto, the research is done on the key performance indicators of the battery.

(2) In the last 3 years, the basic supporting facilities for the charging stations and Charging pile for private parking are funded by the three level governments of Central, Hubei and Yichang .

(3) Central Finance should give policies with preferential electricity pricing for Yichang (public and private)charging equipment and charging piles to give full play to the resource endowments of the' Capital of Hydropower', highlight the charm of the city and improve the attraction of foreign investment.

(4)The joint funds of Hubei and Yichang are arranged to give private purchase, public institution procurement for energy saving or new energy car to financial subsidies.

(5)The pilot of Emission Permit System is carried out and the relevant tests and assessments are implemented in Yichang city proper [4]. The total technical indicators of the energy saving and its annual standards should be put forward respectively from 2018 to 2020. The reward and punishment policies are explored based on the level of automobile fuel consumption. An exit mechanism for public and private cars is established within five years.

6) Central Government allocates funds to support the projects of energy saving and technology innovation for new energy auto, and guides enterprises to increase investment in technological development, engineering, standard setting, and market applications.

\section{Conclusion}

Yichang city has the advantages of location, cost, resources and policy, which provide the basic conditions for the construction of the new energy automobile industry.

In November 1, 2007, National Development and Reform Commission issued the regulations on the management of the access to new energy automobiles. The different standards are set up for the industry entry permission of new energy vehicles at different stages. They are used to determine the different entry conditions. For Yichang, the base of automobile, new energy automobile and its parts industry are weak. It is located in the middle and upper reaches of the Yangtze River, related to the safety of drinking water for the residents of the downstream area. So a more thorough feasibility argument is needed. The high standard of industrial pollution treatment and emission will be the key to Yichang's access to industry permission. It is an urgent and important issue to formulate and implement the scientific and rational development strategy of the automobile industry.

\section{References}

[1] F.Huang and J.Zhu: Journal of Chongqing University of Technology (Social Science), Vol. 29(2015),3:47-51.

[2] Kawahara Eiji: The innovation Era, Vol.11(2010):44-47.

[3] Y.Yang: The analysis of the whole industry chain of the new energy automobile industry, Information on http://mini.eastday.com/mobile/170328160945102.html.

[4] C.G. Xu and Q.H. Xu: Advances in Engineering Research, Vol. 98 (2016):37-40. 